\title{
Response to "Comment on Modeling of single cell cancer transformation using phase transition theory: application of the Avrami equation" by Tez
}

\author{
Krzysztof W. Fornalski ${ }^{1} \oplus \cdot$ Ludwik Dobrzyński $^{1}$
}

Received: 2 December 2021 / Accepted: 5 December 2021 / Published online: 12 January 2022

(c) The Author(s), under exclusive licence to Springer-Verlag GmbH Germany, part of Springer Nature 2021

\section{Sir, Madam,}

We would like to kindly thank for the interesting letter by Tez (2021) as a reply to our recent paper (Fornalski and Dobrzyński 2021). This is an important feedback to our new biophysical model of cellular cancer transformation.

The author (Tez 2021) is perfectly right that the stem cell progeny relationship as well as the lifespan of gastric epithelial cells should be considered in any full-scope model of gastric cancer development. The model presented by Fornalski and Dobrzyński (2021), however, describes just one process: the rapid neoplastic transformation of the cell based on the exact number of mutations, and does not describe the process of mutation accumulation. Therefore the time relationship is very short here, much shorter than the lifespan of cells. More than that, the proposed model is not limited to gastric cancer only, which was selected as an example only.

Anyway, we are open to model modification based on the kind suggestions of Tez, especially because we-as physicists-would benefit from any additional biological and medical knowledge in that matter.

\section{Declarations}

Conflict of interest The authors declare that they have no conflict of interest.

\section{References}

Fornalski KW, Dobrzyński L (2021) Modeling of single cell cancer transformation using phase transition theory: application of the Avrami equation. Radiat Environ Biophys. https://doi.org/10. 1007/s00411-021-00948-0

Tez M (2021) Comment on "Modeling of single cell cancer transformation using phase transition theory: application of the Avrami equation" by Fornalski and Dobrzyński. Radiat Environ Biophys, this volume

Publisher's Note Springer Nature remains neutral with regard to jurisdictional claims in published maps and institutional affiliations.

This reply refers to the comment available online at https://doi.org/ 10.1007/s00411-021-00957-z.

Krzysztof W. Fornalski

krzysztof.fornalski@ncbj.gov.pl

1 National Centre for Nuclear Research (NCBJ), Mokotowska 49, 00-542 Warszawa, Poland 